\title{
Metabolism of Terbufos in Rat Liver
}

\author{
Jin-Tong LI ${ }^{1}$, Shi-Jie SHENG ${ }^{2}$ and Xian-Lin Du ${ }^{1}$ \\ ${ }^{1}$ Institute of Pharmacology and Toxicology, Academy of Military Medical Sciences \\ ${ }^{2}$ National Center of Biomedical Analysis
}

\begin{abstract}
Metabolism of Terbufos in Rat Liver: JinTong LI, et al. Institute of Pharmacology and Toxicology, Academy of Military Medical Sciences, Beijing, China, 100850-Biotransformation of terbufos in rat liver revealed four metabolites in the effluent prepared with a $\mathrm{C}_{18}$ cartridge after the rat liver was perfused for one hour in situ. Analysing the spectrogram of GC-IR and GC-MS, metabolite IV appeared to be an oxidative desulfuration product of terbufos with the formula $\mathrm{C}_{9} \mathrm{H}_{2} \mathrm{O}_{3} \mathrm{PS}_{2}$, the recovery of which in the effluent was $2.13 \%$; metabolite I appeared to be an hydrolysate of metabolite IV with the formula $\mathrm{C}_{5} \mathrm{H}_{13} \mathrm{O}_{3} \mathrm{PS}$, the recovery of which was $0.13 \%$; metabolite II appeared to be an hydrolysate of terbufos with the formula $\mathrm{C}_{5} \mathrm{H}_{13} \mathrm{O}_{2} P S_{2}$, the recovery of which was $2.65 \%$; metabolite III appeared to be a methylate of metabolite II, with the formula $\mathrm{C}_{6} \mathrm{H}_{15} \mathrm{O}_{2} \mathrm{PS}_{2}$, the recovery of which was $1.42 \%$. Relatively the recovery of terbufos was $40.8 \%$. These results were in accord with the regular metabolic pattern in vivo of phosphorothioates with a thioether group.
\end{abstract}

(J Occup Health 1999; 41: 62-68)

Key words: Terbufos, liver metabolism, metabolite, GC-MS, GC-IR

Terbufos is a kind of soil contaminated organophosphorothioate pesticide containing thioether. No reports were seen in literature about its metabolism in rat liver. We studied the biotransformation of terbufos in rat liver perfused in situ, infered proposed pathways for the mammalian hepatic biotransformation of terbufos by four determined metabolites in the effluent, and detcrmined the recoveries of terbufos and its metabolites in the effluent. We preliminarily discussed the effect of the hepatic metabolic activation and detoxification on the toxicity of terbufos and the toxicity of its metabolites.

Received Sep 7, 1998; Accepted Dec 2, 1998

Correspondence to: X.-L. Du, Institute of Pharmacology and Toxicology, Academy of Military Medical Sciences, Beijing, 100850 , P.R. China

\section{Materials and Methods}

\section{Chemicals}

Terbufos (S-ter-butylthiomethy O,O,-diethyl phosphorodithioate) with a 288.42 molecular weight and $91 \%$ purity was purchased from Tian-Jin Pesticides Factory. Bovine serum albumin (BSA) was purchased from Sigma Chemical Co. (electrophoresis grade) and dextran T-40 from Phamacia LKB (Sweden), methanol and ethyl acetate were HPLC grade, and all other chemicals were reagent grade.

\section{Animals}

Male Wistar rats (180-220 g) were obtained from the Laboratory Animal Center of Academy of Military Medical Sciences, and were housed under standard laboratory conditions with free access to water and feed.

\section{Liver Perfusions}

Single-pass liver perfusions in situ were performed as described by Sies". $100 \mu l 0.1 \mathrm{~mol} / l$ Terbufos dissolved in methanol was added to the $100 \mathrm{~m} l$ perfusate reservoir, the perfusate was a modified Krebes-Ringers $\mathrm{NaHCO}_{3}$ buffer containing $0.3 \%$ BSA, $0.5 \%$ dextran T- 40 and $0.3 \%$ glucose. Flow rates were maintained at $5 \mathrm{~m} l /$ liver per min and the length of perfusions was $1 \mathrm{~h}$.

\section{Chemical Analyses}

Before terbufos and its metabolites were qualified and quantified by GC-IR and GC-MS, they were separated with a solid phase extraction (SEP) $\mathrm{C}_{18}$ cartridge (Waters Co.). About $50 \mathrm{ml}$ of effluent was passed though an SEP $\mathrm{C}_{18}$ cartridge and eluted from the cartridge with $5 \mathrm{~m} l$ of ethyl aectate. Then the eluant was dried under a nitrogen stream and the residue was redissolved in $25 \mu l$ of methanol. The concentrated sample was analyzed by GCIR and GC-MS. HEWLETT PACKARD 5890 Series II gas chromatography with flame photometric detection and HEWLETT PACKARD VATRIO-2 TYPE massspectrometer were used, and the infra-red spectrometer was a Bio-Rad FTS-65A. The recoveries of metabolites 


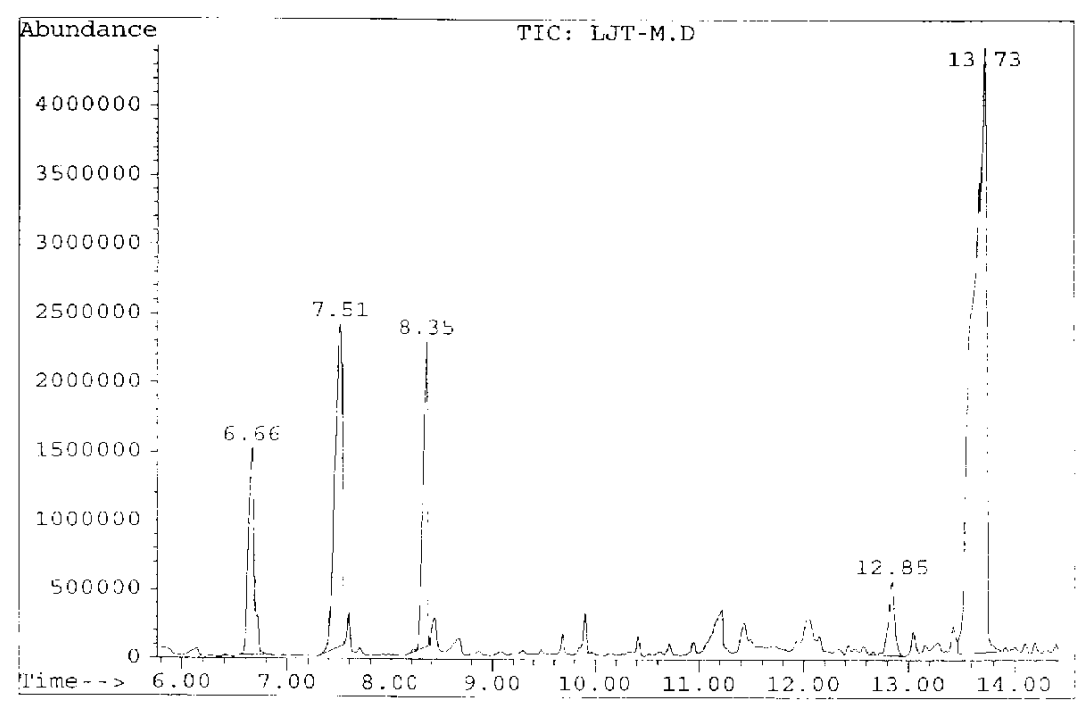

Fig. 1. Gas Chromatogram of Terbufos and its metabolites in rat liver perfusate.

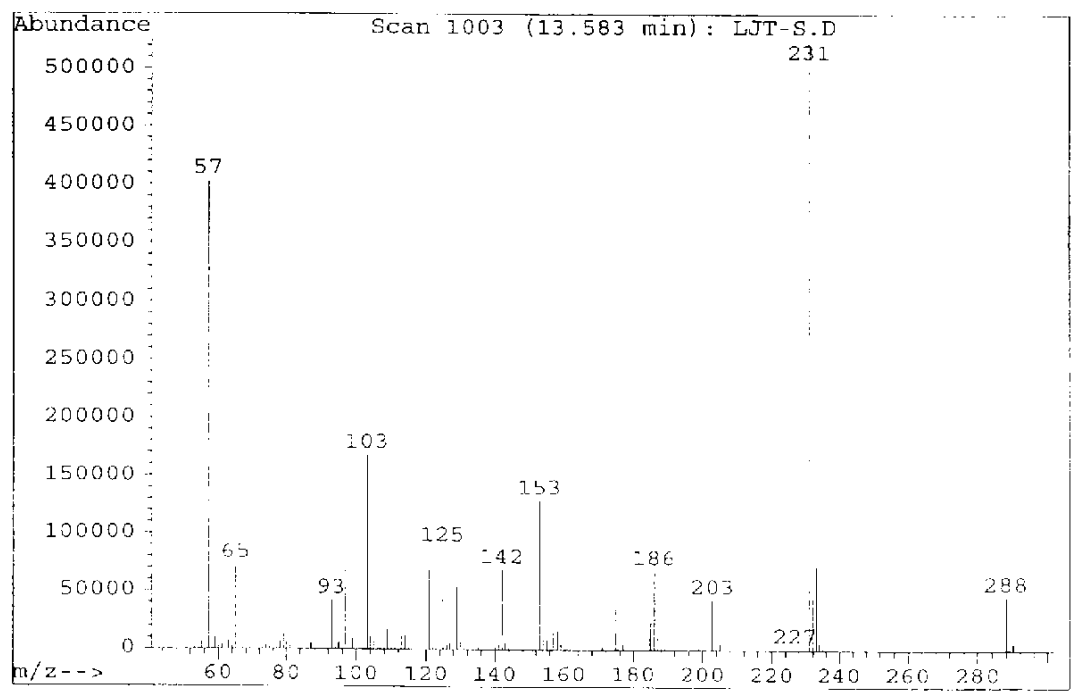

Fig. 2. Mass Spectrum of Terbufos standard.

were expressed as the percentage of the concentration of the parent pesticide entering the liver.

\section{Results}

Gas chromatography and GC-IR analyses of terbufos and its metabolites

The concentration sample was well isolated by gas chromatography, compared with that of blank perfusate. Surplus peaks were examined through characteristic absorption groups in an infra-red spectrometer one by one, particularly the group containing $P$ atoms. As a result, as shown in Fig. 1, there were 5 compounds in the gas chromatograph containing $\mathbf{P}$ atoms, and the retention times (Rt) of whose peaks were $6.66 \mathrm{~min}, 7.51 \mathrm{~min}, 8.35$ $\min , 12.85 \mathrm{~min}$ and $13.73 \mathrm{~min}$, respectively.

Identification of Peak $V(R t=13.73 \mathrm{~min})$ in Fig. $l$

Examination of standard control by GC-MS revealed that its mass spectrum accorded with the mass spectrum of the peak with a retention time of $13.73 \mathrm{~min}$ in Fig. 1 (as shown in Fig. 2 and Fig. 3). Therefore, the peak with the retention time of $13.73 \mathrm{~min}$ in Fig. 1 was determined as terbufos (S-ter-butylthiomethy O,O,-diethyl phosphorodithioate) and its molecular structure was (Fig. 12).

\section{Identification of Peak I ( $R t=6.66 \mathrm{~min})$ in Fig. I}

Peak I ( $\mathrm{t}=6.66 \mathrm{~min}$ ) showed metabolite I. Its 


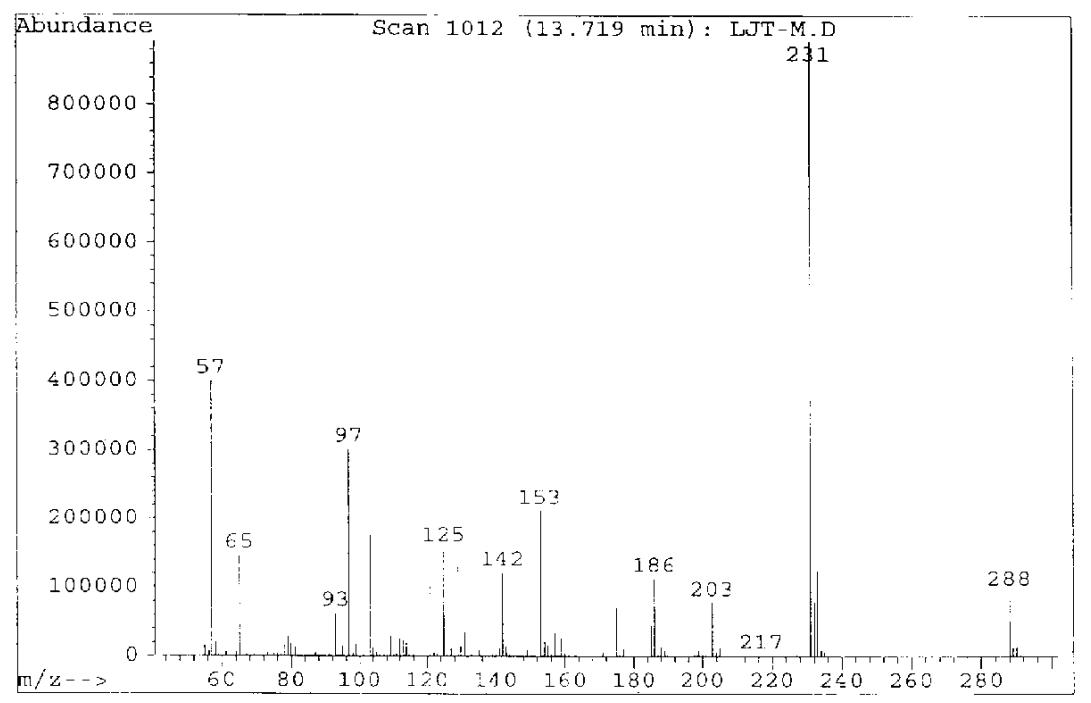

Fig. 3. Mass Spectrum of Terbufos in rat liver perfusate.

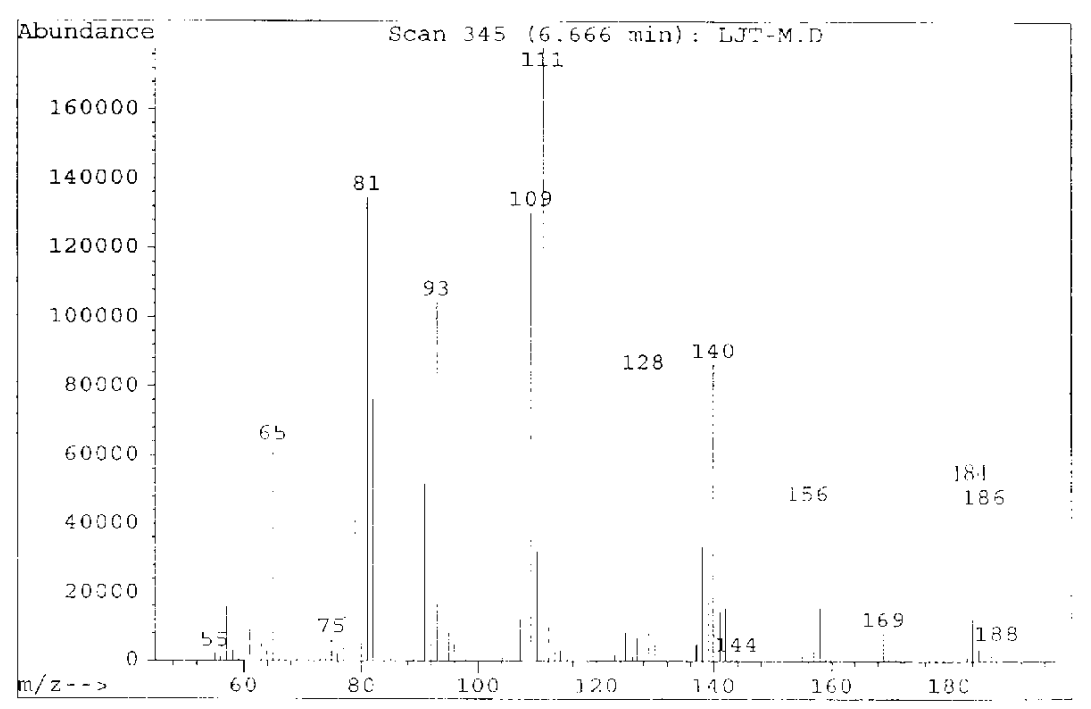

Fig. 4. Mass spectrum of metabolite I in rat liver perfusate.

molecular iron peak and fragment peak (Fig. 4) were completely identified with the mass spectrum of $\mathrm{C}_{5} \mathrm{H}_{13} \mathrm{O}_{3} \mathrm{PS}$ by looking up its mass spectrum in The "Wiley/NBS Registry of Mass Spectral Data"2). This was confirmed by finding that metabolite I had the characteristic absorption group of $\mathrm{P}=\mathrm{O}$ which was seen at $1,280 \mathrm{~cm}^{-1}$ wave velocity in its infrared spectrum (Fig. 5). Therefore, metabolite I could be determined as $\mathrm{C}_{5} \mathrm{H}_{13} \mathrm{O}_{3} \mathrm{PS}(\mathrm{O}, \mathrm{O}$-diethyl-S-methyl phosphorothioate) and its molecular structure is presented in Fig. 12.

\section{Identification of Peak $I I(R t=7.51 \mathrm{~min})$ in Fig. I}

Peak II (Rt=7.51 min) in Fig. 1 showed metabolite II. Its molecular iron peak and fragment peak (Fig. 6) were

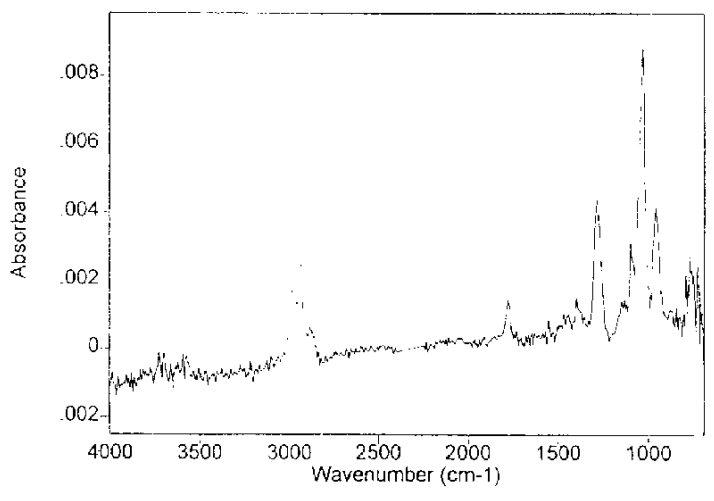

Fig. 5. IR spectrum of metabolite I in rat liver perfusate. 


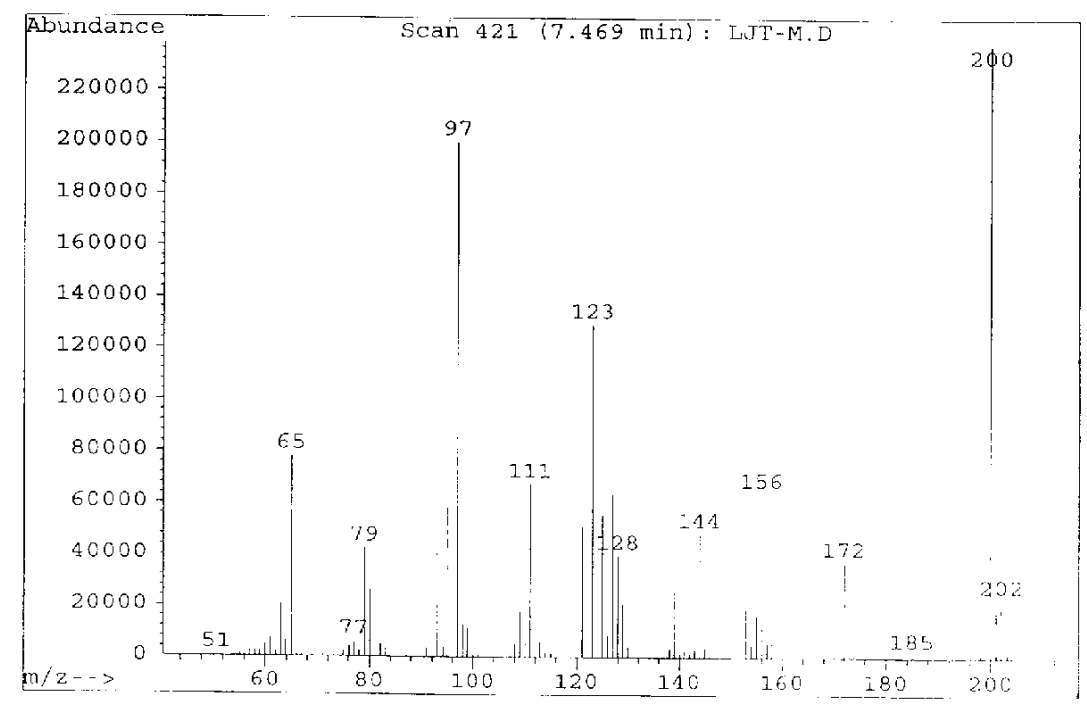

Fig. 6. Mass spectrum of metabolite II in rat liver perfusate.

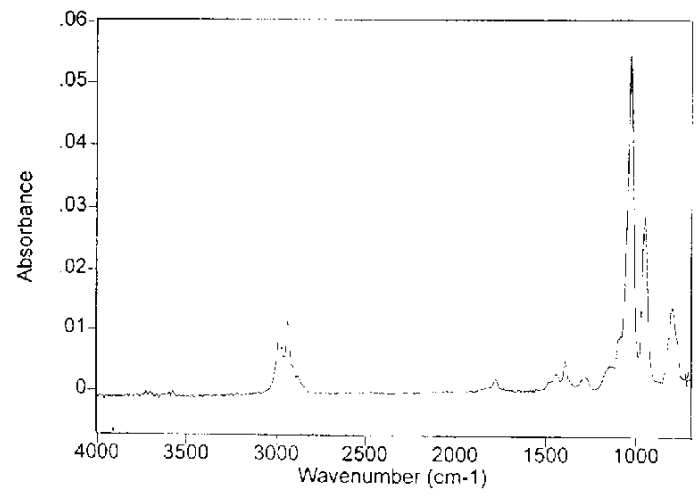

Fig. 7. IR spectrum of metabolite II in rat liver perfusat.

completely identified with the mass spectrum of $\mathrm{C}_{5} \mathrm{H}_{13} \mathrm{O}_{2} \mathrm{PS}_{2}$ by looking up its mass spectrum in the abovementioned Data book. This was also confirmed by finding that metabolite II had the characteristic absorption group of $\mathrm{P}=\mathrm{S}$ which was recognized at $760-780 \mathrm{~cm}^{-1}$ wave velocity in its infra-red spectrum (Fig. 7). Therefore, metabolite II could be determined as $\mathrm{C}_{5} \mathrm{H}_{13} \mathrm{O}_{2} \mathrm{PS}_{2}$ (O,O-diethyl-S-methyl phosphorodithioate) and its molecular structure is presented in Fig. 12.

\section{Identification of Peak III (Rt=8.35 min) in Fig. I}

Peak III ( $\mathrm{Rt}=8.35 \mathrm{~min})$ was metabolite III. Its molecular iron peak and fragment peak (Fig. 8) were rightly identified with the mass spectrum of $\mathrm{C}_{6} \mathrm{H}_{15} \mathrm{O}_{2} \mathrm{PS}_{2}$ by looking up its mass spectrum in the abovementioned Data book. This was also confirmed by finding that metabolite III had the characteristic absorption group of $P=S$ which was recognized at $760-780 \mathrm{~cm}^{-1}$ wave velocity in its infra-red spectrum (Fig. 9). Therefore, metabolite III could be determined as $\mathrm{C}_{6} \mathrm{H}_{15} \mathrm{O}_{2} \mathrm{PS}_{2}(\mathrm{O}, \mathrm{O}, \mathrm{S}$-tricthyl dithiophophate) and its molecular structure is presented in Fig. 12.

\section{Identification of Peak IV $(R t=12.85 \mathrm{~min})$ in Fig. I}

Peak IV ( $\mathrm{Rt}=12.85 \mathrm{~min}$ ) showed metabolite IV, its molecular iron peak was 272 and decreased 16 particles less than compared with the molecular iron of terbufos, suggesting that metabolite IV was an oxidatied desulfuration product (oxon derivant) of terbufos. In its mass spectrum, the primary peak was $215 \mathrm{~m} / \mathrm{e}$, base peak was $171 \mathrm{~m} / \mathrm{e}$, and another main fragment peak was $57 \mathrm{~m} /$ e (Fig. 10). Analysis of their formation in the mass spectrum was as follows: first, $\mathrm{S}$-methyl of metabolite IV was $\beta$-eliminated as $\left(\mathrm{C}_{2} \mathrm{H}_{5} \mathrm{O}\right){ }_{2} \mathrm{POSCH}_{2} \mathrm{~S}^{+}(\mathrm{m} / \mathrm{e} 215)$ and $\mathrm{C}^{+}\left(\mathrm{CH}_{3}\right)_{3}(\mathrm{~m} / \mathrm{e} \mathrm{57})$, then $\mathrm{C}_{2} \mathrm{H}_{5} \mathrm{OPOHSCH}_{2} \mathrm{~S}^{+}(\mathrm{m} / \mathrm{e}$ 171) was formed from $\left(\mathrm{C}_{2} \mathrm{H}_{5} \mathrm{O}\right)_{2} \mathrm{POSCH}_{2} \mathrm{~S}^{+}(\mathrm{m} / \mathrm{e} 215)$ by breaking down a ${ }^{+} \mathrm{C}_{2} \mathrm{H}_{4} \mathrm{O}(\mathrm{m} / \mathrm{c} 44)$ and rearranging $\mathrm{H}^{+}$. In further analysis of the infra-red spectrum of metabolite IV (Fig. 11), at $1280 \mathrm{~cm}^{-1}$, wave velocity and characteristic absorption group of $\mathrm{P}=\mathrm{O}$ were recognized. Therefore, metabolite IV could be determined as $\mathrm{C}_{9} \mathrm{H}_{2} \mathrm{O}_{3} \mathrm{PS}_{2}$ ( $\mathrm{S}$ ter-butylthiomethy $\mathrm{O}, \mathrm{O}$,-diethyl phosphorothioate) and its molecular structure is presented in Fig. 12.

Recovery of terbufos and its metabolites in the effluent

As shown in Table 1: In the effluent of rat liver perfused in situ, the recovery of terbufos was $40.8 \%$, and the recovery of metabolites I, II, III and IV was $0.13 \%$, $2.65 \%, 1.42 \%$ and $2.13 \%$, respectively.

\section{Discussion}

Many organophosphorus pesticides such as 


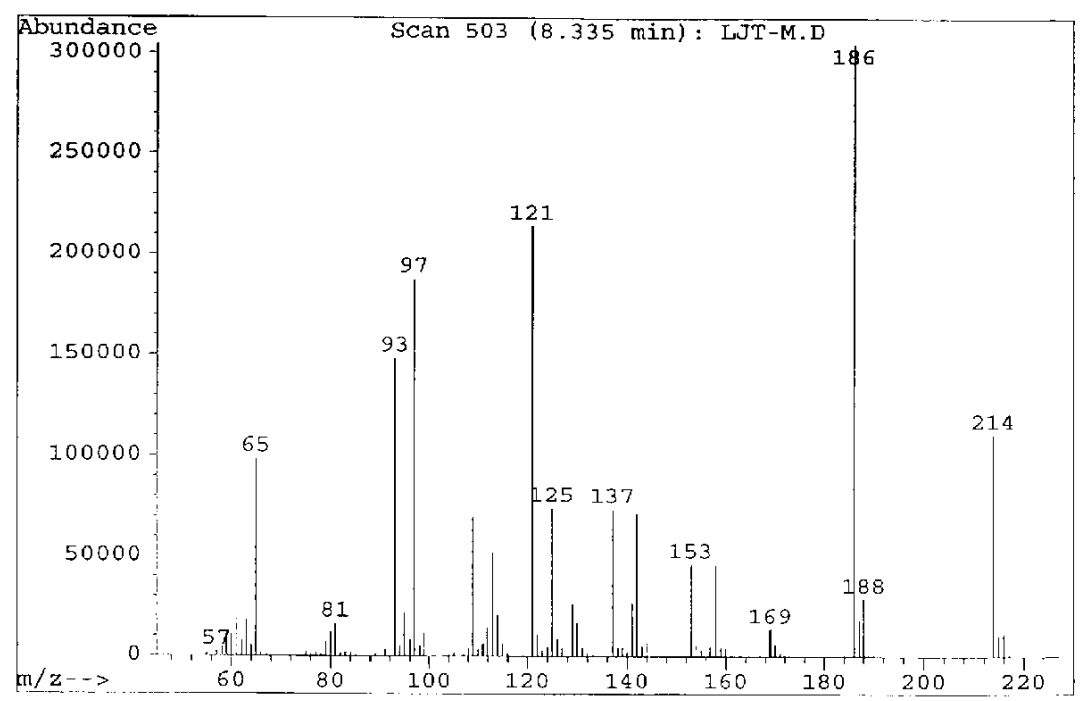

Fig. 8. Mass spectrum of metabolite III in rat liver perfusate.

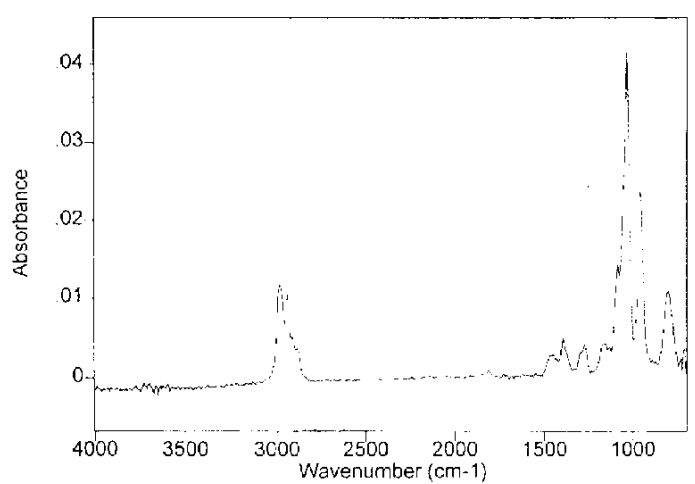

Fig. 9. IR spectrum of metabolite III in rat liver perfusate.

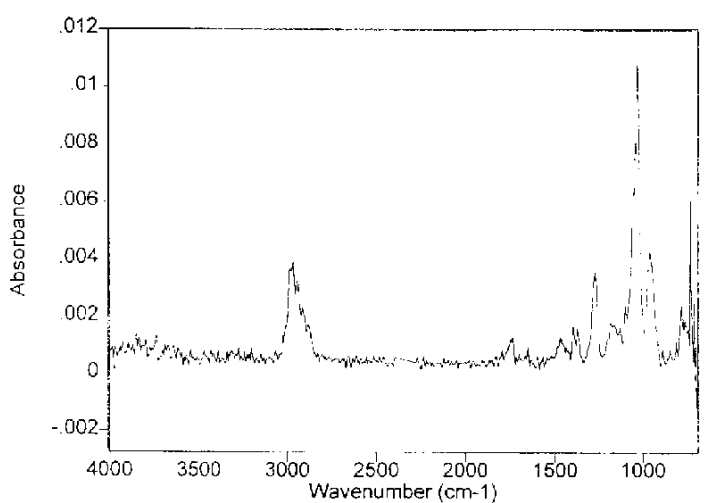

Fig. 11. IR spectrum of metabolite IV in rat liver perfusate.

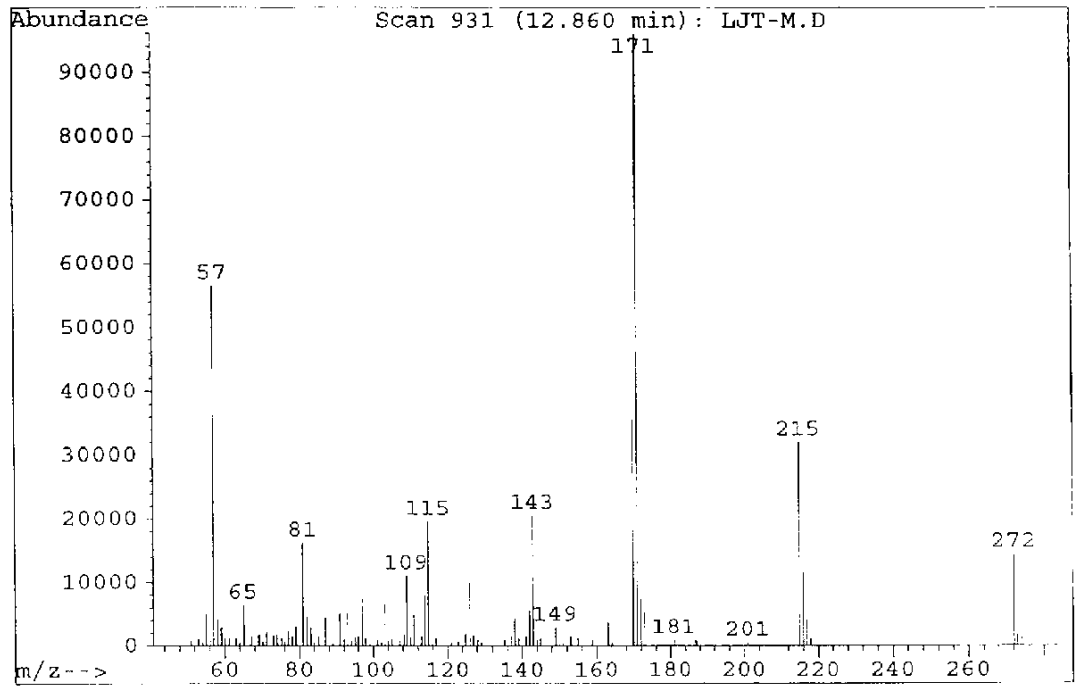

Fig. 10. EI-MS spectrum of metabolite IV in rat liver perfusate. 
<smiles>CO[P+]([O-])(OC)SC</smiles><smiles>[PbH2][PbH2]</smiles>

(184)<smiles>CCCOP(=S)(OCCC)SCSC(C)(C)C</smiles>

$$
\mathrm{C}_{9} \mathrm{H}_{21} \mathrm{O}_{2} \mathrm{PS}_{3}
$$

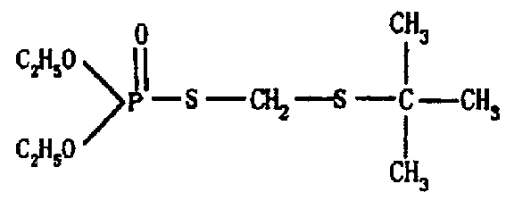<smiles>COP(=S)(OC)SC</smiles>

$$
\mathrm{C}_{5} \mathrm{H}_{13} \mathrm{O}_{2} \mathrm{PS}_{2}
$$<smiles>CCCCCCCCOP(=S)(OCC)OCCC</smiles>

$\mathrm{C}_{6} \mathrm{H}_{15} \mathrm{O}_{2} \mathrm{PS}_{2}$

(214)

Fig. 12. Molecular structures of terbufos and its metabolites. phosphorothioate undergo metabolic activation to form the corresponding oxons, which are potent inhibitors of cholinesterase, but these ox ons can undergo further biotransformation (detoxification) once formed within the liver $^{3)}$. Metabolic activation is mainly oxidation reaction catalyzed by cytochrome $\mathbf{P}-450$ dependent monooxygenases, including oxidatived desulfuration of phosphorothioate, formation of sulphoxides and sulphones, formation of amine oxides and $O$ dealkylation ${ }^{4,5,6)}$. Among them, oxidatived desulfuration may be the most important activation. Four main routes of hepatic detoxification have potential importance in toxicity levels ${ }^{7,8)}$. The first, cytochrome P-450 mediated dearylation of phosphorothionates; the second, aliesterases should be able to destroy a significant amount of the oxons; the third, the $\mathrm{Ca}^{++}$-dependent A-esterases, are capable of catalytic oxon hydrolysis; and the fourth, glutathione (GSH) conjugation, is a potential route of xenobiotic detoxification. In addition, methylation of phosphorothioate is supposed to be a detoxification pathway".

In mammals, the relative rates of formation and detoxification of oxons are important factors in determining their acute toxicities ${ }^{7.10)}$. In our results, metabolite $1 \mathrm{~V}$ (terbufos oxon) is an oxidatived desulfuration product of terbufos which reaction was catalyzed by cytochrome P-450 located in the liver microsome, and its recovery in the effluent is $2.13 \%$. Metabolite I is a hydrolysate of metabolite IV which reaction was catalyzed by A-esterase located in the liver microsome and mitochondrion, and its recovery was $0.13 \%$; Meanwhile, metabolite II is hydrolysate of terbufos which reaction was also catalyzed by A-esterase located in the liver microsome and mitochondrion, and its recovery was $2.65 \%$. But metabolite III was a methylate of metabolite II which reaction was suggested to be a detoxification reaction catalyzed by SAM methyl transferase, and its recovery was $1.42 \%$. Relatively, the recovery of terbufos is $40.8 \%$. Sulphoxides and sulphones were not detected in the effluent. These results are

Table 1. Recovery of terbufos and metabolites in effluent

\begin{tabular}{cccccc}
\hline & \multicolumn{5}{c}{ Effluent perfusate } \\
\cline { 2 - 6 } Preparation* & $\begin{array}{c}\text { Parent } \\
\text { compound (\%) }\end{array}$ & $\begin{array}{c}\text { Metabolite } \\
\text { I }(\%)\end{array}$ & $\begin{array}{c}\text { Metabolite } \\
\text { II }(\%)\end{array}$ & $\begin{array}{c}\text { Metabolite } \\
\text { III (\%) }\end{array}$ & $\begin{array}{c}\text { Metabolite } \\
\text { IV (\%) }\end{array}$ \\
\hline 1 & $42.7 \pm 0.4$ & $\mathbf{0 . 1 0 \pm 0 . 0 4}$ & $2.48 \pm 0.35$ & $1.53 \pm 0.15$ & $1.30 \pm 0.05$ \\
2 & $42.8 \pm 0.3$ & $0.20 \pm 0.03$ & $3.78 \pm 0.29$ & $1.55 \pm 0.04$ & $3.03 \pm 0.01$ \\
3 & $37.0 \pm 1.7$ & $0.10 \pm 0.01$ & $2.04 \pm 0.21$ & $1.00 \pm 0.28$ & $2.07 \pm 0.58$ \\
Mean \pm SD & $40.8 \pm 3.3$ & $0.13 \pm 0.06$ & $2.65 \pm 0.98$ & $1.42 \pm 0.37$ & $2.13 \pm 0.87$
\end{tabular}

*Each preparation was made by three liver perfusions. "Values are expressed as the percentages of the concentration of the parent pesticide entering each liver. 
accorded with the regular metabolic pattern of phosphorothioate with thioether in mammals ${ }^{9)}$.

Nevertheless, it is worth mentioning that metabolites I, II and III are all triakylphosphrothioates analogues. Although the major of these compounds caused cholinergic signs, in some, second phase toxicity affecting the lung was also seen ${ }^{1-13)}$. Histopathological studies revealed that the lung lesion is initiated from damage caused by type I pneumocytes and subscquent proliferation of type II pneumocytes which lead to progressive diffuse interstitial thickening in adult rat lung ${ }^{(4,15)}$. These compounds can also interfere with normal biochemical and physiological maturity of fetal lung through intrauterine exposure ${ }^{16,17)}$. Lung injury could precipitate hypercapnia to result in hypothermia ${ }^{18)}$. Study on the structure and pulmonary toxicity relationship indicated that $S$-alkyl moieties are residues determining whether a compound mainly induces pulmonary or acute cholinergic symptoms ${ }^{12,13)}$. Furthermore, it must be remembered that the hepatic metabolism of terbufos is complex, potentially involving several simultaneous and sequential reactions, so that liver perfusion studies only give partial information regarding specific metabolic steps, and more details of the metabolism of terbufos and the toxicological action of its metabolites await further research.

\section{References}

1) Sies $\mathbf{H}$. The use of perfusion of liver and other organs for the study of microsomal electron-transport and cytochrome P-450 systems. Methods in Enzymol 1978; 52: 48-59.

2) Fred W, Laffertv MC. The Wiley/NBS Registry of Mass Spectral Date Wiley-Interscience publication, 1986: $773,1052,1317$.

3) Cheng R-Y and Liu L-Z. Chemistry of Organophosphorus Pesticides Shanghai: Shanghai Science and Technology Press, 1995: 79-80.

4) Coats CR. Insecticide Mode of Action. Academic Press, 1982: 163.

5) Gage JC. A cholinesterase inhibition derived from o,odiethyl o-p-nitrophenyl thiophosphate in vivo. Biochem J 1953; 54: 426.

6) Levi PE, Hodgson E. Monooxyenation: Interaction and expression of toxicity. Inseticide Action from Molecule to Organism Plenum Press, 1989: 233-244.
7) Chambers JE, Ma T, Boone JS, Chambers HW. Role of detoxication pathways in acute toxicity levels of phosphorothionate insecticides in the rat. Life Sci 1994; 54: 1357-1364.

8) Vitarius JA, Sultatos LG. The role of calcium in the hydrolysis of the organophosphate paraoxon by human serum A-esterase. Life Sci 1995; 56: 125-134.

9) Morifusa Eto. Organophosphorus Pesticides Organic and Biological Chemistry. Ohio: Cranwood Parkway Cleveland, 1974: 161-162.

10) Vitarius JA, O'Shaughnessy JA, Sultatos LG. The effects of phenobarbital pretreatment on the metabolism and toxicity of paraoxon in the mouse. Pharmacol Toxicol 1995; 77: 16-22.

11) Vershoyle RD, Cabral JRP. Investigation of the acute toxicity of some trimethyl and triethyl phosphrothioates with particular reference to those causing lung damage. Arch Toxicol 1982; 51: 221-231.

12) Hasegawa J, Wada Y, Sageshima M, Suzuki M, Kamiyama S, Abe N, Koizumi A. Structure and pulmonary toxicity relationship on $\mathrm{O}, \mathrm{O}$-dimethyl $\mathrm{S}$ alkyl phosphorothioate esters. Pharmacol Toxicol 1990; 66: 367-372.

13) Aldridge WN, Nemery B. Toxicology of trialkylphosphorothioates with particular reference to lung toxicity. Fundam Appl Toxicol 1984; 4: 215-223.

14) Aldridge WN, Dinsdale ED, Nemery B, Verschyle RD. Some aspects of the toxicity of trimethyl and triethyl phosphorothioates. Foudam Appl Toxicol 1985; 5: 4760.

15) Gandy J, Imamaru T. Cellular responses to $O, O, S$ trimethyl phosphorothioate-induced pulmonary injury in rats. Toxicol Appl Pharmacol 1985; 80: 51-57.

16) Koizumi A, Sageshima $M$, Wada $Y$, Narita $S$, Higuchi $S$. Neonatal death and lung injury in rats caused by intrauterine exposure to $\mathrm{O}, \mathrm{O}, \mathrm{S}$-trimethyl phosphorothioate. Arch Toxicol 1988; 61: 378-386.

17) Koizumi A, Sageshima M, Wada Y, Narita S, Higuchi S. Immature alveolar/blood barrier low disaturated phosphatidylcholine in fetal lung after intrauterine exposure to $\mathrm{O}, \mathrm{O}, \mathrm{S}$-trimethylphosphorothioate. Arch Toxicol 1989; 63: 331-335.

18) Ohtaka K, Hamade N, Yamazaki Y, Suzuki M, Koizumi A. A direct involvement of the central nervous system in hypophagia and inhibition of respiratory rate in rats after treatment this $0,0, S$-trimethyl phosphorothioaye. Arch Toxicol 1995; 69: 559-564. 